This is a postprint version of the following published document:

Serrano, B., Levenfeld, B., Bravo, J. \& Baselga, J.

(1996). Studies of Polymerization of Acrylic

Monomers Using Luminescence Probes and

Differential Scanning Calorimetry. Polymer

Engineering \& Science, 36 (2), pp. 175-181.

DOI: $10.1002 /$ pen. 10399

(C) Wiley, 1996 


\title{
Studies of Polymerization of Acrylic Monomers Using Luminescence Probes and Differential Scanning Calorimetry
}

\author{
BERNA SERRANO, BELÉN LEVENFELD, JULIO BRAVO, and \\ JUAN BASELGA* \\ Departamento de Ingenieria, Escuela Politécnica Superior \\ Universidad Carlos III de Madrid \\ 28911 Leganés, Spain
}

\begin{abstract}
A fiber optic system has been designed to couple calorimeter and fluorimeter equipment for in situ monitoring of polymerization reactions by both techniques simultaneously. Two acrylic monomers (cyclohexyl methacrylate, CHM, and 2-eth-ylhexyl acrylate, EHA) were studied at different temperatures. Pyrene (Py) was employed at a low concentration $\left(\leq 10^{-4} \mathrm{~mol} / \mathrm{L}\right)$ as a fluorescence probe. The emission spectrum of pyrene shows a broad band peaking at $390 \mathrm{~nm}$, whose intensity grows with polymerization progress. A correlation with conversion degree could be established by collecting fluorescence intensity through the optical fiber at different polymerization times. For the more flexible polymer formed, poly(ethyl-hexyl acrylate) (PEHA), Py emission sharply increases only when high conversions are reached and continues increasing for a long time after the limiting conversion is attained. For CHM polymerizations, S-shaped curves are found. Isochronal plots of intensity vs. scaled conversion allow elaboration of master curves for the peak emission. Data at $50^{\circ} \mathrm{C}$ for $\mathrm{CHM}$ cannot be fitted to the master curve, and this is explained in terms of vitrification.
\end{abstract}

\section{INTRODUCTION}

$\mathrm{T}$ he most common. fluorescence techniques for monitoring polymerization reactions involve the introduction of a probe in the reaction mixture. These extrinsic probes are usually present in such small quantities that they do not interfere with the progress of polymerization and are sensitive to changes in local microenvironments. Information regarding extent of monomer conversion, onset of the gel effect, and/or vitrification may be determined "in situ" by following the changes in probe fluorescence properties throughout the reaction.

A class of probes called molecular rotors was employed for the first time by Loufty $(1,2)$, to follow the progress of a series of methacrylate polymerizations. It was reported that the rotational relaxation of the probes is sensitive to free volume, which affects the microscopic mobility and the fluorescence intensity.

Since then a number of different probes and techniques have been reported and reviewed recently by Torkelson et al. (3). Among them should be mentioned the molecular rotors mentioned above, excimer probes, and reactive dye labels. Excimers are a class of fluorescent probes [for example, 1,3,-bis(1-pyrenyl)propane] that have been employed to monitor the cure process of epoxy resins or acrylic polymerizations (4-6). In excimer probes, excimer formation normally requires some kind of intramolecular rotation, and so this process is sensitive to free volume (7). The ratio of monomer to excimer emission intensities can be correlated to conversion because of the associated loss of free volume.

Sung et al. (8-10) have shown the usefulness of employing reactive dyes as extrinsic probes for monitoring the polymerization of epoxy resins or polyurethanes. The dyes incorporate into the polymer in the addition reaction and their photophysical properties change after the reaction initiates. This is a major difference with respect to molecular rotors or excimer probes, which are suitable for high conversion studies. Recently, Torkelson et al. (3) have reported a similar approach applied to acrylic monomers, using a fluorene methacrylate derivative which cancels its self-quenching behavior when incorporated into the polymer chain. This molecule when copolymerized provides information about the course of the polymerization over a broad conversion range. 
Several experimental setups may be used for monitoring isothermal polymerization reactions. Normally fluorescence and conversion are determined in separate experiments and correlated via the polymerization time. It is thus necessary to be very careful in matching experimental conditions for a proper correlation to be done.

One of the most promising features of luminescent techniques is that they allow in situ measurements with the aid of light guides. Optical fibers have been used recently for monitoring polymerization reactions (11). In this work, a simple alternative experimental setup is presented, which obviates time correlations and allows isochronal plots of fluorescence intensity and conversion even for quick reactions. A differential scanning calorimeter is employed with a slightly modified sample holder, which allows the insertion of an optical fiber to illuminate and collect light.

Industrial applications of fluorescence monitoring techniques may include adhesives and organic matrix composites. Low conversion sensing may be of practical interest when pot-life must be controlled. However, in-service performance of adhesives or composites is very highly dependent on the adequacy of the cure cycle to which they are subjected. High conversion sensing, vitrification, or post-polymerization sensing find here their natural area of application. In this work, pyrene has been selected as a probe that senses the local free volume availability (12) during a polymerization reaction.

The polymerization of two different acrylic monomers, cyclohexyl methacrylate (CHM) and 2-ethylhexyl acrylate (EHA), is studied in this work. These monomers give rise to polymers with very different glass transition temperatures $(13,14)$ and so it is possible to study the pyrene emission behavior at high conversion in very different microhydrodynamic regimes.

\section{experTMENTAL}

\section{Materials}

The monomers used were cyclohexyl methacrylate, CHM (Sigma), and 2-ethylhexyl acrylate, EHA (Fluka). They were freed of inhibitor, dried, and distilled twice under nitrogen at reduced pressure. The middle fraction was collected and stored at $-25^{\circ} \mathrm{C}$.

The initiator, 2,2'-azobis-isobutyronitrile, AIBN (Fluka), and pyrene, Py (Eastman Kodak) were both recrystallized twice from methanol and stored in the dark at $-25^{\circ} \mathrm{C}$.

\section{Differential Scanning Calorimetry}

The bulk isothermal polymerization of $\mathrm{CHM}$ and EHA was investigated using a differential scanning calorimeter (Perkin-Elmer DSC-7), at 50, 70, and $90^{\circ} \mathrm{C}$.

Two series of experiments were run. The first one was carried out only with monomer and initiator in order to obtain the kinetic parameters of polymeriza- tion. In the second one, Py was added to the reaction mixture to monitor the polymerization simultaneously with fluorescence as described below.

\section{Fluorescence Spectroscopy}

The steady state fluorescence measurements were performed on a Perkin Elmer LS-3 fluorimeter. Spectral conditions were: 5 and $10 \mathrm{~nm}$ slits for excitation and emission respectively, and $\lambda_{\text {exc }}=315 \mathrm{~nm}$. Uncorrected spectra were recorded from 325 to $550 \mathrm{~nm}$.

\section{Coupled System DSC-FS}

The coupled system used in this work was built by us and employs a randomized bifurcated fiber bundle system ("Y" configuration). One bundle was employed for excitation and the other to collect the emission.

The common bundle was inserted in the DSC sample holder enclosure. It was fixed at a distance from the sample to give the maximum fluorescence signal without perturbation of the heat flux inside the DSC oven. In Fig. 1, a drawing of the instrumentation setup is presented. Illumination is done only in the sample holder and, since the light intensity that emerges from the optical fiber is small, only a minor baseline optimization must be performed on the DSC.

\section{Experimental Methods}

Reaction mixtures were prepared by the addition of initiator to the monomer, at a constant concentration of $1 \mathrm{wt} \%$. Portions of this solution were weighed (15 $\mathrm{mg}$ ) into ordinary open aluminum DSC sample pans. Conversion at different reaction times was calculated from the area between the DSC curve and the baseline, which was obtained by back-extrapolation after the polymerization was finished. The residual monomer content was determined by heating the sample from the polymerization temperature to $200^{\circ} \mathrm{C}$ at $10^{\circ} \mathrm{C} / \mathrm{min}$. Each experiment was repeated at least 3 times to check the reproducibility.

When using the coupled system, pyrene was added at a very low concentration $\left(\leq 10^{-4} \mathrm{~mol} / \mathrm{L}\right)$ to the reaction mixture. Open sample pans were used also to perform fluorescence measurements. In order to avoid thermal damage of the optical assembly, the sample was not heated at $200^{\circ} \mathrm{C}$ after the polymerization. The

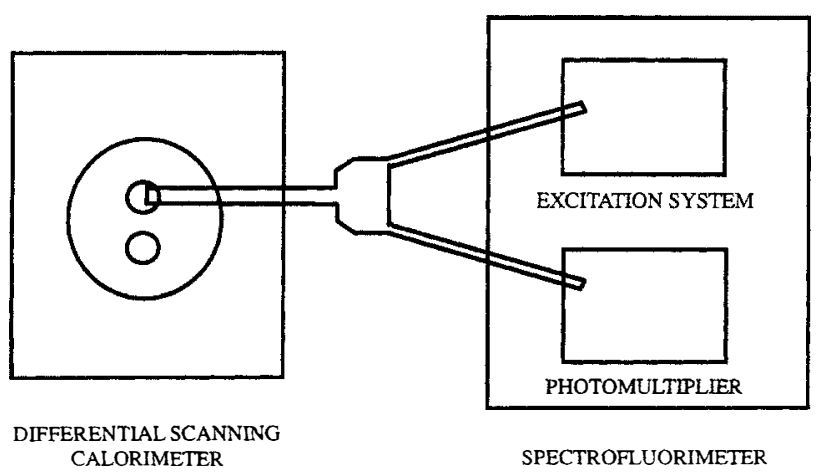

Fig. 1. Schematic experimental setup. 
residual monomer content data were obtained from previous experiments. Fluorescence intensity at the emission maximum was collected along the polymerization time, although in some experiments full emission spectra were taken at different reaction times to check the invariance of the pyrene emission spectrum shape.

\section{RESULTS AND DISCUSSION}

\section{Differential Scanning Calorimetry}

No significant differences were observed between the thermograms obtained with and without illumination. The variation in exothermic peak times and polymerization heats remain within $5 \%$ and $10 \%$, respectively.

Figures 2 and 3 show the thermograms for the isothermal bulk polymerization of CHM and EHA at 50, 70 , and $90^{\circ} \mathrm{C}$. In both cases, the reaction time decreases with increasing temperature. It can also be observed that EHA polymerization runs faster than CHM.

The polymerization heat at each temperature was obtained from the areas under the curves using the standard Perkin-Elmer peak integration software. The total heat of polymerization was calculated adding the residual monomer polymerization heat. These results are given in Table 1 for both monomers.

The polymerization conversion can be expressed as a function of time, using the following equation:

$$
\alpha_{t}(\%)=100 \frac{[M]_{0}-[M]}{[M]_{0}}=100 \frac{Q_{t}}{Q_{T}}
$$

where $[M]$ and $[M]_{0}$ are actual and initial monomer concentration, respectively; $Q_{t}$ is the reaction heat corresponding to the partial area under the curve up to time $t$; and $Q_{T}$ is the total heat of polymerization at this temperature.

Figures 4 and 5 show the conversion variation (\%) with time for each system. The final conversions ob-

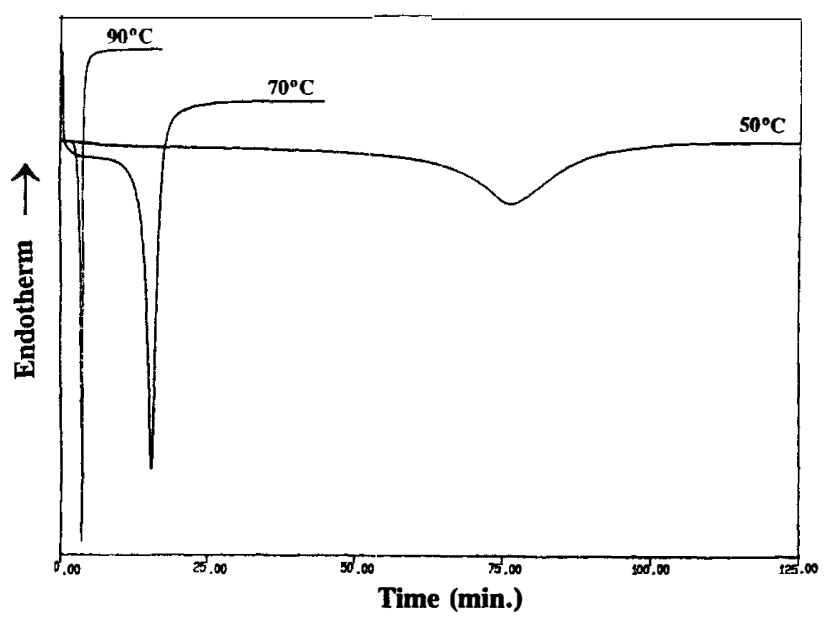

Fig. 2. DSC thermograms of isothermal bulk polymerization of cyclohexyl methacrylate in the presence of 1 wt\% 2,2'-azobisisobutyronitrlle at the temperatures indicated at the curves.

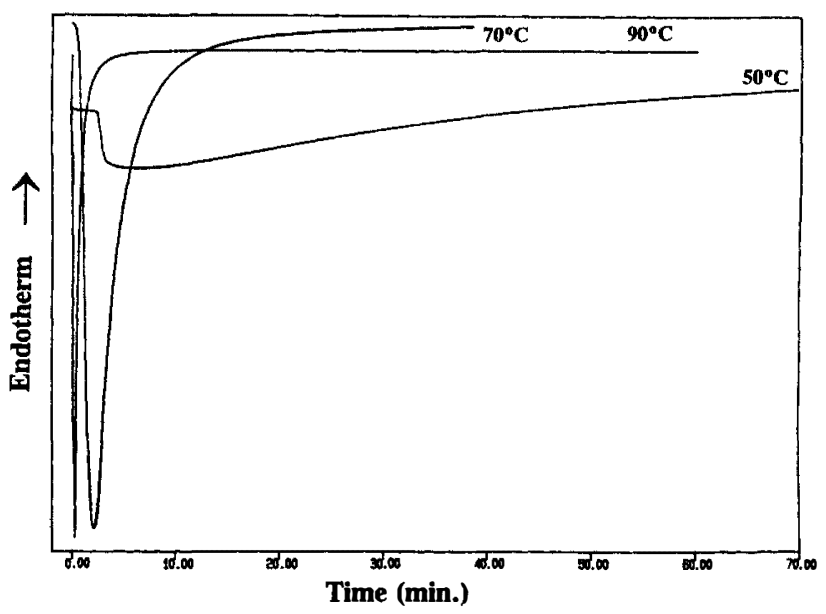

Fig. 3. DSC thermograms of isothermal bulk polymerization of ethylhexyl acrylate in the presence of 1 wt\% 2,2'-azobisisobutyronitrile at the temperatures indicated at the curves.

Table 1. Heats of Polymerization (kJ/mol) and Residual Monomer (wt\%) for the Isothermal Bulk Polymerization of Cyclohexyl Methacrylate and Ethylhexyl Acrylate in the Presence of 1 wt\% 2,2' -Azobis-Isobutyronitrile.

\begin{tabular}{cccc}
\hline Monomer & $\begin{array}{c}\text { Polymerization } \\
\text { Temperature } \\
\left({ }^{\circ} \mathbf{C}\right)\end{array}$ & $\begin{array}{c}\text { Heat of } \\
\text { Polymerization } \\
\text { (kJ/mol) }\end{array}$ & $\begin{array}{c}\text { Residual } \\
\text { Monomer } \\
\text { (wt\%) }\end{array}$ \\
\hline CHM & 50 & 41 & 21.3 \\
& 70 & 50 & 9.6 \\
& 90 & 54 & 3.2 \\
EHA & 50 & 54 & 0.53 \\
& 70 & 69 & 0.30 \\
& 90 & 65 & 0.23
\end{tabular}

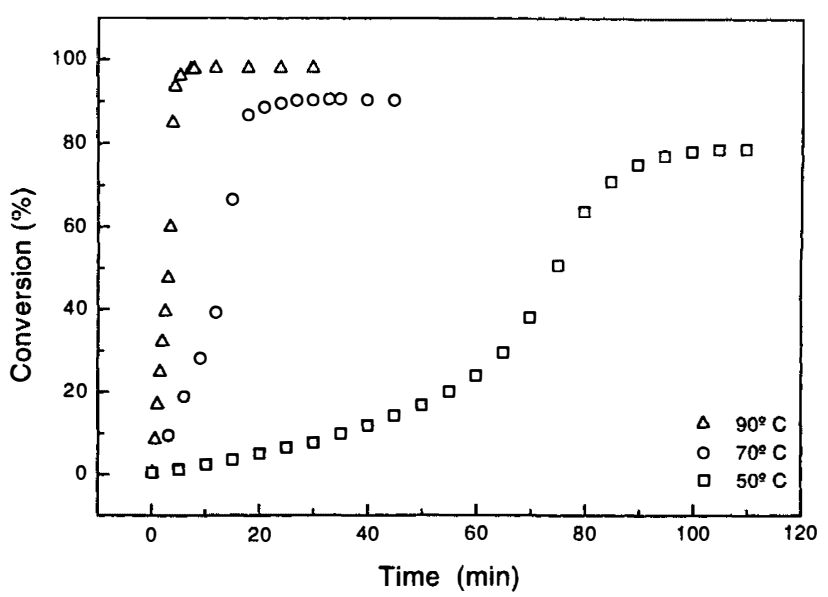

Fig. 4. Plots of conversion-time for cyclohexyl methacrylate in the presence of $1 w t \% 2,2^{\prime}$-azobis-isobutyronitrile at the temperatures indicated at the curves.

tained for EHA are higher than for CHM. These results are in good agreement with the typical behavior of acrylates and methacrylates $(15,16)$. The reported $T_{g}$ values for poly(cyclohexyl methacrylate)(13) (PCHM) and poly(ethylhexyl acrylate) (14) (PEHA) are $83^{\circ} \mathrm{C}$ and $-50^{\circ} \mathrm{C}$, respectively. The polymerization temperatures 


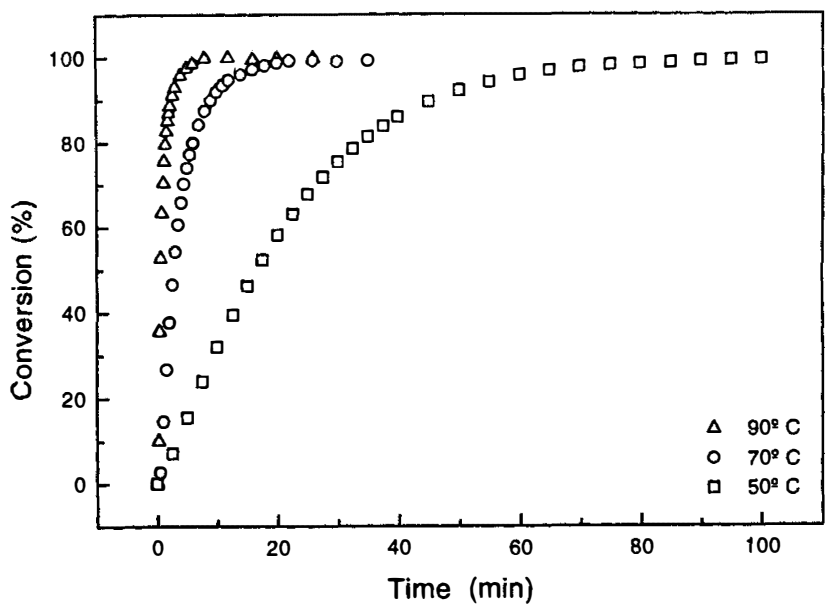

Fig. 5. Plots of conversion with time for ethylhexyl acrylate in the presence of $1 \mathrm{wt} \% 2,2^{\prime}$-azobis-isobutyronitrile at the temperatures indicated at the curves.

used in this work are well above $T_{g}$ for PEHA, while for PCHM they are in the range of its $T_{g}$ and so lower limiting conversions must be expected.

For both monomers, the polymerization obeys the steady-state condition, i.e., being first-order with respect to the monomer concentration at the early stages of the reaction. It is known that the classical free radical kinetics is valid only at low conversion degrees. As the reaction proceeds, the polymer concentration and the viscosity of the reaction mixture increase. The chain termination rates are therefore diminished and the overall polymerization becomes diffusion controlled, i.e., the gel effect sets in (17).

The initial kinetic rate constant, $K^{\prime}$, can be calculated using $E q 2$, assuming a first-order reaction with respect to the monomer and that the initiator concentration is independent of time,

$$
\ln \left(\frac{1}{1-\alpha}\right)=K^{\prime} t
$$

where

$$
K^{\prime}=K_{p}\left(\frac{2 f K_{d}}{K_{t}}\right)^{1 / 2}[I]_{0}^{1 / 2}
$$

$K_{p}, K_{d}$, and $K_{t}$ are the rate constants for propagation, initiator dissociation, and termination, respectively; $f$ the initiator efficiency; and $\left[I_{O}\right.$ its initial concentration.

Figures 6 and 7 show that for the early stages of reaction, straight lines are obtained, which justify the use of Eq 2. The overall rate constants calculated from the linear part of the curves for both monomers are given in Table 2.

Overall activation energy for the polymerization of both monomers was calculated using conventional Arrhenius treatment. The values obtained were 43 and $39 \mathrm{~kJ} / \mathrm{mol}$ for CHM and EHA, respectively.

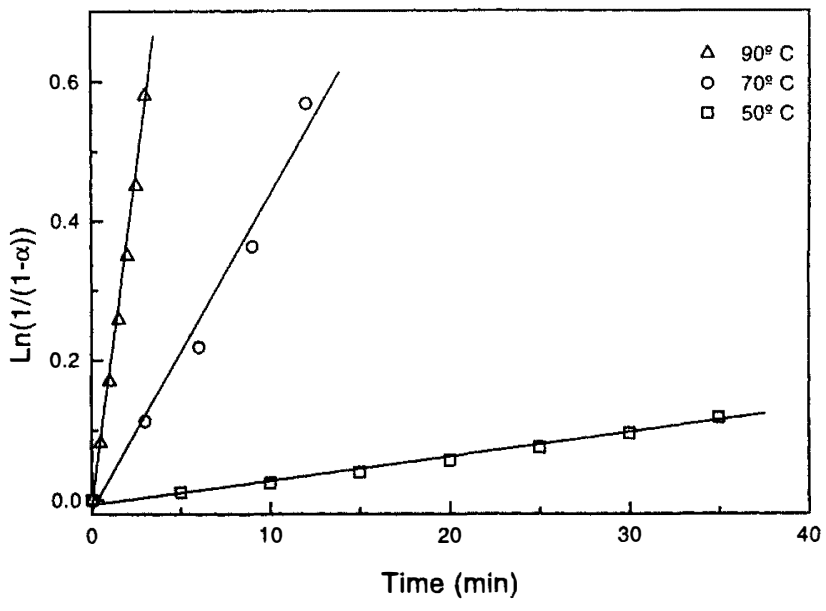

Fig. 6. Determination of initial rate constants for isothermal bulk polymerization of cyclohexyl methacrylate in the presence of $1 w t \% 2,2^{\prime}$-azobis-tsobutyronitrile at different temperatures.

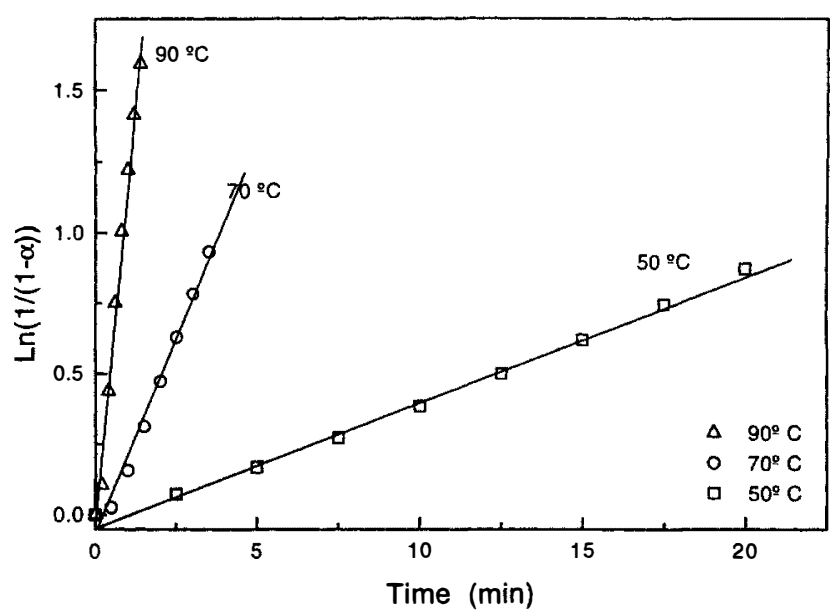

Fig. 7. Determination of initial rate constants for isothermal bulk polymerization of ethylhexyl acrylate in the presence of 1 wt\% 2,2'-azobis-isobutyronitrlle at different temperatures.

Table 2. Initial Rate Constants $\left(\min ^{-1}\right)$ for the Isothermal Bulk Polymerization of Cyclohexyl Methacrylate and Ethylhexyl Acrylate in the Presence of 1 wt\% 2,2'-AzobisIsobutyronitrile.

\begin{tabular}{ccc}
\hline Monomer & $\begin{array}{c}\text { Polymerization } \\
\text { Temperature }^{\left({ }^{\circ} \mathbf{C}\right)}\end{array}$ & $\begin{array}{c}\text { Initial Rate } \\
\text { Constant }\left(\mathbf{m i n}^{-\mathbf{1}}\right)\end{array}$ \\
\hline $\mathrm{CHM}$ & 50 & $3.0410^{-3}$ \\
& 70 & $3.6110^{-2}$ \\
& 90 & $2.0910^{-1}$ \\
EHA & 50 & $4.010^{-2}$ \\
& 70 & $2.810^{-1}$ \\
& 90 & 1.20 \\
\hline
\end{tabular}

\section{Fluorescence}

Figure 8 depicts emission spectra of pyrene in CHM at $50^{\circ} \mathrm{C}$ using the fiber optic coupling as a function of polymerization time. Pyrene shows an emission maximum centered at $390 \mathrm{~nm}$, whose intensity increases with time and whose final fluorescence intensity, in 
Fig. 8. Emission spectra of pyrene in $\mathrm{CHM}$ at $50^{\circ} \mathrm{C}$ as a function of the polymerization time, using the coupled DSC-FS system.

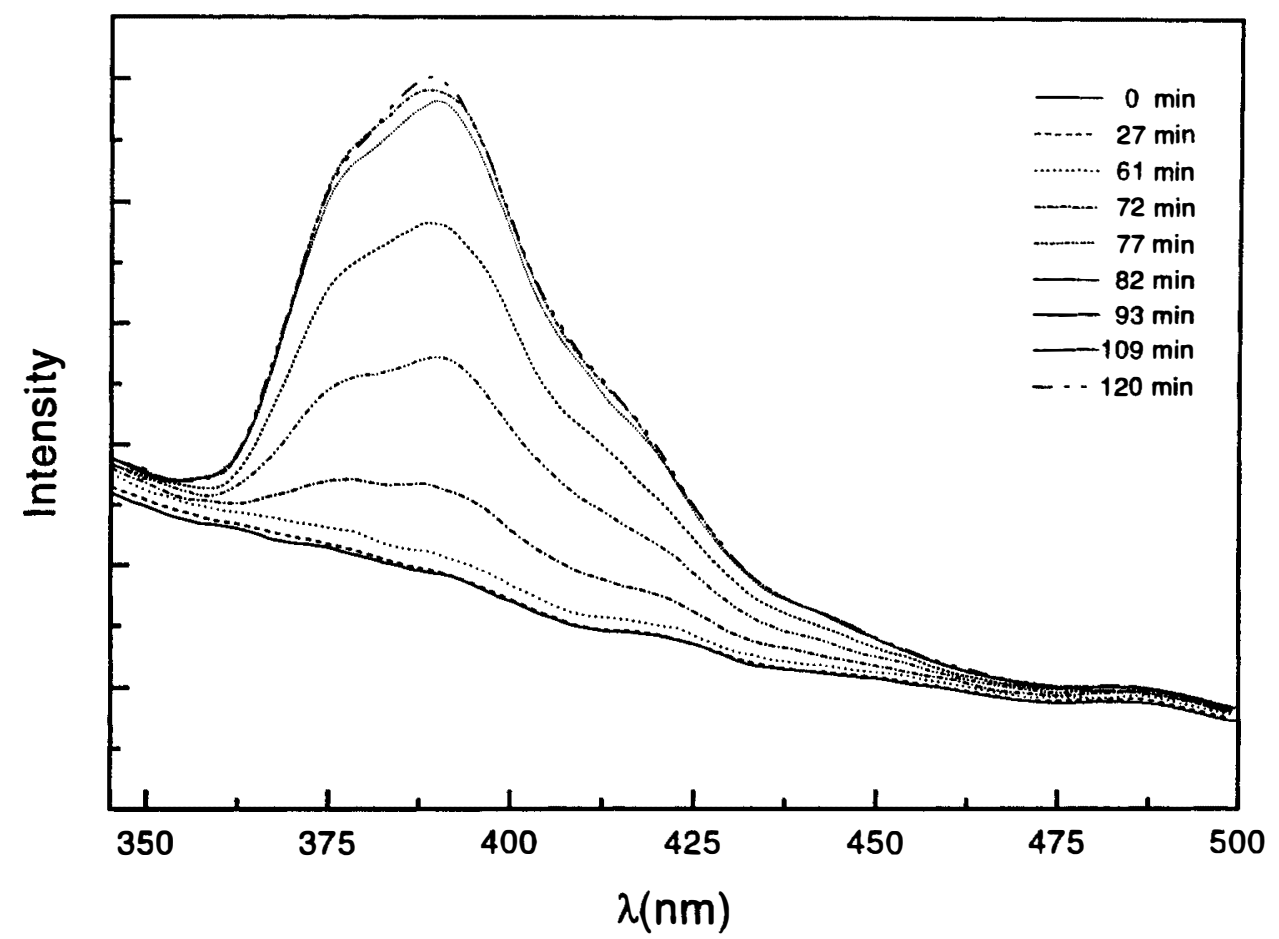

the range of polymerization times studied in this work, is about three to six times the initial one. All the spectra for CHM and EHA at different temperatures show the same shape.

For CHM, the course of the polymerization was followed by the relative increase of the fluorescence intensity at $390 \mathrm{~nm}, I_{R}$. $I_{R}$ was obtained by subtracting the initial intensity and normalizing it at the maximum constant value obtained in each experiment.

Figure 9 shows the change in $I_{R}$ with polymerization time for $\mathrm{CHM}$ at different temperatures. $I_{R}$ remains almost constant in time until a critical moment is reached when a sharp rise in fluorescence intensity occurs. The S-shaped fluorescence intensity dependence on polymerization time is a common behavior to

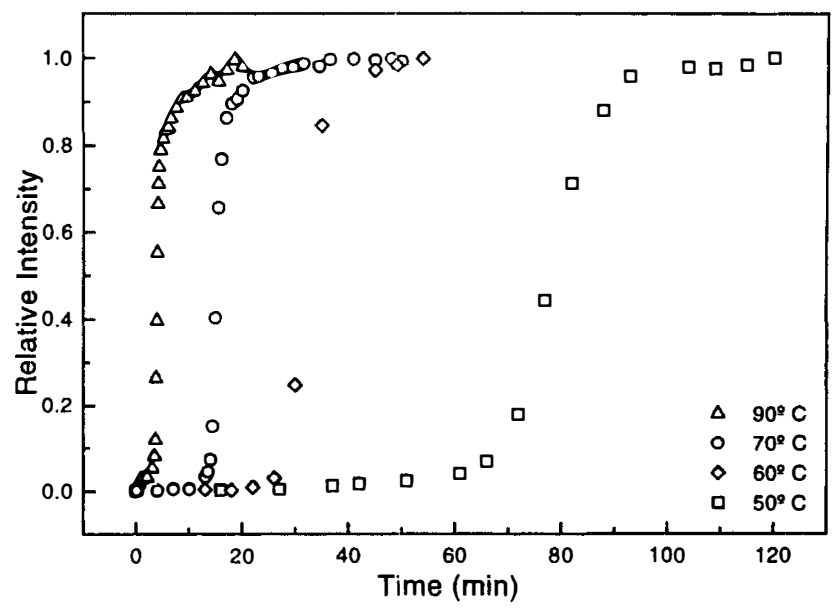

Fig. 9. Relative fluorescence intensity of pyrene in CHM at different temperatures as a function of the polymerization time. all temperatures studied for this monomer. However, the lag period and the slope of the fluorescence rise depend strongly on the polymerization temperature and do not match the conversion-time profiles, as is evident from the comparison between Fig. 4 and Fig. 9 . In Table 3, a comparison between fluorescence and conversion time profiles is shown. The fluorescence onset may be defined as the intersection between the tangent to the initial linear portion of the intensitytime curve and the extrapolated maximum slope. The Fl. onset data for each temperature is listed in the second column of Table 3, and it may be pointed out its coincidence with the exothermic peak times. Since the latter are usually assigned to the gel effect onset (18), it seems that pyrene begins to emit significantly when the polymerization becomes diffusion controlled. The critical conversion at the fluorescence onset increases with temperature as expected for diffusion controlled reactions.

Other important features of pyrene emission are: a) once the critical conversion is reached, the slope of the fluorescence rise is much higher than the rate at which conversion increases; b) the conversion at which pyrene emission begins to level off is very close to the limiting conversion achieved in each particular experiment, but when it has been reached, pyrene emission keeps an increasing trend.

Figure 10 depicts the variation of the fluorescence intensity with polymerization time at 50,60 , and $90^{\circ} \mathrm{C}$ for EHA. The time profile differs markedly from that observed for CHM. The initial lag period is present only for the lower temperatures $\left(50\right.$ and $60^{\circ} \mathrm{C}$ ) and appears to be absent for the higher temperatures. For the low temperatures, even at very high polymeriza- 
Table 3. Fluorescence and Conversion Data for $\mathrm{CHM}$ at Different Temperatures.

\begin{tabular}{|c|c|c|c|c|c|c|c|c|}
\hline \multirow[b]{2}{*}{$T\left({ }^{\circ} \mathrm{C}\right)$} & \multirow{2}{*}{$\begin{array}{l}\text { FI. Onset } \\
\text { (min) }\end{array}$} & \multirow{2}{*}{$\begin{array}{l}\text { FI. Offset } \\
\text { (min) }\end{array}$} & \multirow{2}{*}{$\begin{array}{l}\text { Conv. at FI } \\
\text { Onset }^{\ddagger}\end{array}$} & \multirow{2}{*}{$\begin{array}{c}\text { Conv. at FI } \\
\text { Offset }^{\ddagger}\end{array}$} & \multirow{2}{*}{ Lim. } & \multirow{2}{*}{$\begin{array}{c}\text { Exth. } \\
\text { Peak* (min) }\end{array}$} & \multicolumn{2}{|c|}{ Maximum Slope } \\
\hline & & & & & & & Conv. $\left(\min ^{-1}\right)$ & FI. $^{*}\left(\right.$ a.u. $\left.\min ^{-1}\right)$ \\
\hline $\begin{array}{l}50 \\
60 \\
70 \\
90\end{array}$ & $\begin{array}{l}68.4 \\
27 \\
14.4 \\
3.6\end{array}$ & $\begin{array}{l}86.3 \\
35 \\
16.3 \\
4.2\end{array}$ & $\begin{array}{l}36 \\
52 \\
77 \\
65\end{array}$ & $\begin{array}{l}67 \\
85 \\
84 \\
82\end{array}$ & $\begin{array}{l}78 \\
88 \\
90 \\
90\end{array}$ & $\begin{array}{r}71.6 \\
30.8 \\
14.5 \\
3.6\end{array}$ & $\begin{array}{l}0.033 \\
0.07 \\
0.095 \\
0.68\end{array}$ & $\begin{array}{r}10 \\
29 \\
135 \\
330\end{array}$ \\
\hline
\end{tabular}

t Time at which fluorescence rises: FI. Onset; time at which fluorescence levels off: Fl. Offset.

$\mp$ Conversion in \% at fi. onset or fi. offset.

5 Maximum constant conversion obtained.

Time at the exothermic peak in the DSC thermograms.

* The slope for the fluorescence increase is calculated from the absolute intensity-time profiles.
"The

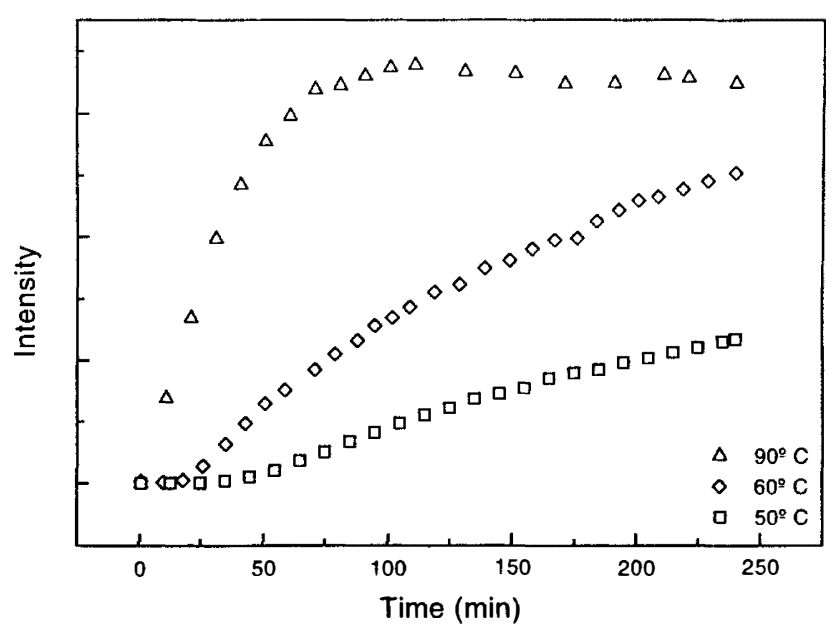

Fig. 10. Intensity of fluorescence of pyrene in EHA at different temperatures as a function of the polymerization time.

tion times, no third stage is found. The intensity plateau is only observed at $90^{\circ} \mathrm{C}$.

In Table 4, the main features of the conversion and intensity time profiles are presented. In contrast to CHM results, the exothermic peak time and the fluorescence onset are not correlated. The conversion slopes found for EHA are approximately the same as the ones found for CHM, but the fluorescence slopes are around one order of magnitude lower than for CHM. This different behavior must be attributed to the higher conformational flexibility of PEHA. Because of the low $T_{g}$ of this polymer, at the polymerization temperatures employed in this work, the free volume availability is not the controlling factor for excited state pyrene relaxation in almost the full conversion range.

\section{Isochronal Plots of Relative Fluorescence Intensity and Scaled Conversion}

EHA and CHM monomers are interesting systems for studying the pyrene response in three different polymerization regimes: a) far from the $T_{g}$ of the forming polymer, b) near the $T_{g}$ of the polymer, and c) in the vitrification process.

EHA is a good example of a polymerizing system far away from $T_{g}$. The variation of relative fluorescence intensity against scaled conversion is presented in Fig. 11. Since it is difficult to obtain total conversion with the actual experimental setup, it seems convenient to employ scaled conversions. This allows us to check if the mechanism that causes the excited state pyrene relaxation is independent of the polymerization temperature. Figure 11 represents the master curve for the EHA system and shows that pyrene may be a good probe for sensing very high conversion. At the present moment, the nature of this very high conversion process remains unknown.

In Figure 12, the corresponding master curve for $\mathrm{CHM}$ is presented. Data at 60,70 , and $90^{\circ} \mathrm{C}$ superimpose fairly well, showing that in this temperature range the origin of the excited pyrene relaxation is the same at these temperatures. Data at $50^{\circ} \mathrm{C}$ can not be fitted properly to the master curve, deviating at about $70 \%$ of conversion from the general behavior. This different habit for the $50^{\circ} \mathrm{C}$ data may be attributed to the appearance of a vitrification process at this polymerization temperature. Vitrification is associated with the insufficiency of thermal energy for holding up the dynamic conformational equilibrium of the formed polymer. In the vitrification region, conversion may continue to increase, at a lower rate, several percent more but, because of polymer rigidity, without the

Table 4. Fluorescence and Conversion Data for EHA at Different Temperatures.

\begin{tabular}{|c|c|c|c|c|c|c|c|c|}
\hline \multirow[b]{2}{*}{$T\left({ }^{\circ} \mathrm{C}\right)$} & \multirow{2}{*}{$\begin{array}{l}\text { FI. Onset } \\
\text { (min) }\end{array}$} & \multirow{2}{*}{$\begin{array}{l}\text { Fl. Offset } \\
\text { (min) }\end{array}$} & \multirow{2}{*}{$\begin{array}{l}\text { Conv. at FI } \\
\text { Onset }^{\ddagger}\end{array}$} & \multirow{2}{*}{$\begin{array}{l}\text { Conv. at FI } \\
\text { Offset }^{\ddagger}\end{array}$} & \multirow{2}{*}{$\begin{array}{c}\text { Lim. } \\
\text { Conv. } 5\end{array}$} & \multirow{2}{*}{$\begin{array}{c}\text { Exth. } \\
\text { Peak* (min) }\end{array}$} & \multicolumn{2}{|c|}{ Maximum Slope } \\
\hline & & & & & & & Conv. $\left(\min ^{-1}\right)$ & Fl.* (a.u. $\left.\min ^{-1}\right)$ \\
\hline 50 & 47 & - & 64 & - & 70 & 8 & 0.020 & 0.76 \\
\hline 60 & 19 & - & 87 & - & 95 & 3 & 0.16 & 2 \\
\hline 90 & - & 50 & - & 90 & 90 & 0.2 & 0.63 & 6.25 \\
\hline
\end{tabular}

Time at which fluorescence rises: FI. Onset; time at which fluorescence levels off: FI. Offset.

Conversion in \% at fl. onset or fl. offset.

5 Maximum constant conversion obtained.

* Time at the exothermic peak in the DSC thermograms.

* The slope for the fluorescence increase is calculated from the absolute intensity-time profiles. 


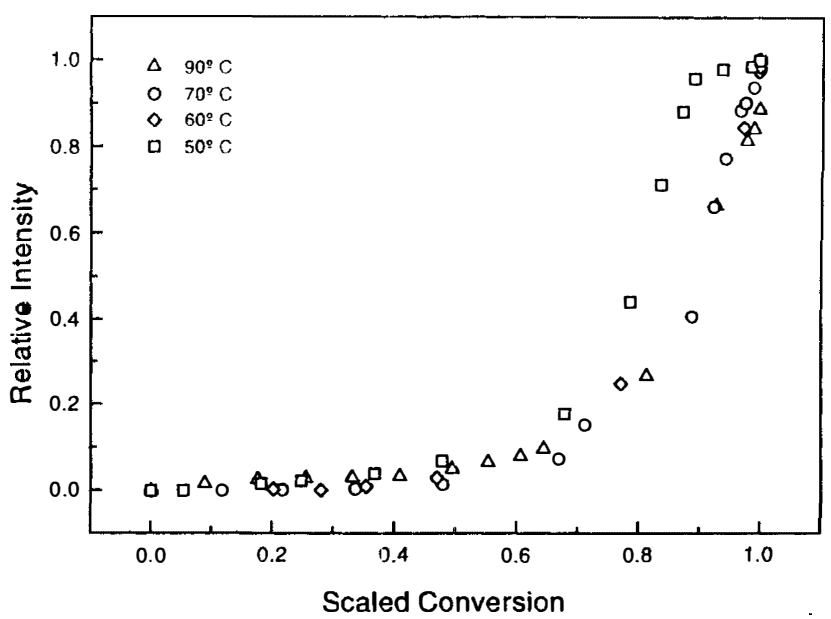

Fig. 11. Isochronal plot of relative fluorescence intensity and scaled conversion for pyrene in CHM at different temperatures.

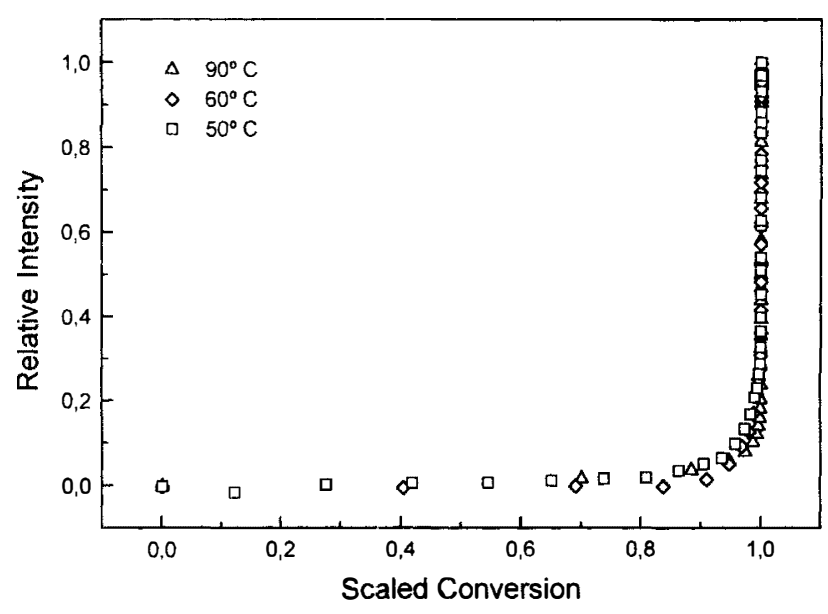

Fig. 12. Isochronal plot of relative fluorescence intensity and scaled conversion for pyrene in EHA at different temperatures.

corresponding volume change. This interpretation may explain why Py emission levels off while conversion continues growing until the limiting conversion is reached. To the authors' knowledge, there is no specific method reported in the literature for fluorescent sensing of a vitrification process. Further work is being done to determine exactly the origin of this striking behavior.

\section{Conclusions}

A simple experimental setup has been developed for monitoring polymerization reactions and other ther- mal transitions, measuring simultaneously fluorescence and calorimetry. It has been applied to the polymerization of two monomers, EHA and CHM, which give rise to polymers with quite different $T_{g} \mathrm{~s}$. The kinetic parameters of the polymerization of both monomers have been determined.

It has been demonstrated that pyrene is a good probe for sensing polymerization reactions at high conversions.

It is reported that pyrene fluorescence response is different when vitrification takes place in the polymerization reaction. Isochronal plots of relative fluorescence intensity against scaled conversion are useful for detecting the appearance of the vitrification process.

\section{ACKNOWLEDGMENTS}

The authors acknowledge the financial support of this work by the Consejería de Educación of Comunidad de Madrid (CAM 247/92) and the Comisión Interministerial de Ciencia y Tecnología (MAT93-0823).

\section{REFERENCES}

1. R. O. Loufty, Macromolecules, 14, 270 (1981).

2. R. O. Loufty, Pure Appl. Chem., 58, 1239 (1986).

3. R. E. Miller, E. L. Burch, F. D. Lewis, and J. M. Torkelson, J. Polym. Sci., Polym. Phys. Ed., 32, 2625 (1994).

4. A. Stroeks, M. Shmorhun, A. M. Jamieson, and R. Simha, Polymer, 29, 467 (1988).

5. F. W. Wang, R. E. Lowry, and B. M. Fanconi, Polymer, 27, 1529 (1986).

6. King-Fu Lin and W. Wang, Polymer, 35, 687 (1994).

7. J. Bravo, F. Mendicuti, and W. Mattice, J. Polym. Sci.: Polym. Phys. Ed., 32, 1511 (1994).

8. C. S. P. Sung, I.-J. Chi, and W.-C. Yu, Macromolecules, 18, 1510 (1985).

9. W.-C. Yu and C. S. P. Sung, Macromolecules, 23, 386 (1990).

10. E. Pyun and C. S. P. Sung, Macromolecules, 24, 855 (1991).

11. W. Dang and N. Sung, Polym. Eng. Sci., 34, 707 (1994).

12. J. E. Guillet, in Phtophysical and Photochemical Tools in Polymer Science, NATO ASI series, Chap. 4, page 472 (1985).

13. J. Van Turnhout, Polym. J. (Japan), 2, 173 (1971).

14. C. E. Rehberg, C. H. Fisher, Ind. Eng. Chem., 40, 1429 (1948).

15. T. Malavasic, U. Usredkar, I. Anzur, and I. Vizovisek, J. Macromol. Sct. Chem., A19, 987 (1983).

16. T. Malavasic, I. Vizovisek, U. Usredkar, and I. Anzur, J. Polym. Sci. Polym. Symp., 69, 73 (1981).

17. E. Trommsdorff, H. Koehle, and P. Lagally, Makromol. Chem., 1, 169 (1947).

18. T. Malavasic, U. Usredkar, I. Anzur and I. Vizovisek, J. Thermal Anal., 29, 697 (1984). 